\title{
Moving Technologies from the Test Tube to Commercial Products
}

\author{
Robert G. Bryant \\ NASA Langley Research Center \\ Hampton, VA 23681
}

Abstract:

Successful technologies include objects, processes, and procedures that share a common theme; they are being used to generate new products that create economic growth. The foundation is the invention, but the invention is a small part of the overall effort. The pathway to success is understanding the competition, proper planning, record keeping, integrating a supply chain, understanding actual costs, intellectual property (IP), benchmarking, and timing. Additionally, there are obstacles that include financing, what to make, buy, and sell, and the division of labor i.e. recognizing who is best at what task. Over the past two decades, NASA Langley Research Center (LaRC) has developed several commercially available technologies. The approach to the commercialization of three of these inventions; Langley Research Center-Soluble Imide (LaRC-SI, Imitec Inc.), the Thin Layer Unimorph Driver (THUNDER, FACE International), and the Macrofiber Composite (MFC, Smart Material Corp.) will be described, as well as some of the lessons learned from the process. What makes these three inventions interesting is that one was created in the laboratory; another was built using the previous invention as part of its process, and the last one was created by packaging commercial-off-the-shelf (COTS) materials thereby creating a new component.

Introduction:

\section{LaRC-SI Resin}

First synthesized in the early 90's under NASA's High Speed Research (HSR) program, LaRC-SI was developed as a high temperature matrix resin for advanced composites, and a hot melt adhesive for metallic bonding. LaRC-SI belongs to a class of high performance polymers called polyimides (PI), chiefly a polyetherimide (PEI). This class of aromatic polymers has demonstrated capabilities such as forming durable thin films, tough molded mechanical parts, strong adhesive bonds, and resilient dielectric coatings. [1-2] Like many PEIs, LaRC-SI can be produced into useful articles by liquid resin casting or melt processing from the dry powder.

Polymeric material can be obtained from both steps in the polymerization process. The solution processing of the PAA resin (first step) is used to form films and coatings by applying the resin, or varnish, to a substrate and then heating the coated substrate well above the glass transition temperature (Tg) of the resulting PI or PEI to drive off the solvent and cyclodehydrate the PAA. The advantage of this process is that very thin coatings and films can be produced from polymers whose melt viscosity is so high that melt processing is difficult if not nearly impossible. After the second step, the isolated PI or PEI powder can then be melt processed, having a reasonable melt viscosity, into complex shapes. If the powder cannot be readily melt processed, it may yield to direct hot-forming into stock billets for machining.

What was unexpected about LaRC-SI was that it remained soluble as both the PAA and the PEI, even at solids above $50 \%(\mathrm{w} / \mathrm{w})$ allowing the solution casting of resin from either step. Additionally, the PEI powder can be directly obtained by mixing the PEI solution with a common solvent that precipitates the PI out of solution. The LaRC-SI powder can be re-dissolved into a high boiling polar amide solvent if it is not heated above its glass transition temperature $(\mathrm{Tg})$. Once it is heated above its $\mathrm{Tg}$, it becomes insoluble and thus highly inert, but retains its thermoplastic behavior i.e. melt processability. Thus, after the addition of the monomers, each of the three processing steps can produce a useful product. [3-6]

\section{THUNDER Actuator}


The THUNDER actuator is based on the unimorph concept where a piezoelectric wafer is bonded to a metal shim that is used to facilitate the mounting of the wafer, and to amplify its out-of-plane motion through a mechanical pre-stress applied to the device during processing. This mechanical stress manifests itself by affording a unimorph that has a bicurved configuration (Figure 1). This pre-stress is generated by using a high-temperature hot-melt adhesive that laminates the components (metal and ceramic) together well above room temperature. As the bonded laminate cools, the difference in the coefficient of thermal expansion (CTE) between the metallic layer and the ceramic causes a mechanical pre-stress to occur as the materials contract at different rates during cooling. This pre-stress causes a uniform strain on the ceramic, from the metal layer that produces a curved spring (Figure 2). [7-15]

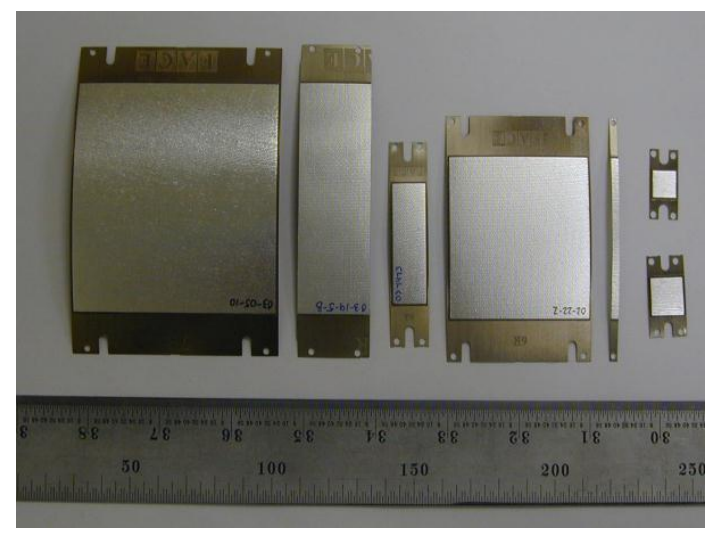

Figure 1. THUNDER Actuators (FACE International).

In addition to the standard off-axis motion that the "unimorph effect" produces, referred to as $\mathrm{d}_{33}$, where the " 3 " indicates the direction of the electric field and measured displacement, this device has the additional effect of a mechanical leaf spring. This allows tailoring the design of the THUNDER wafer to efficiently balance its mechanical output against a predetermined load. [12,14,15]
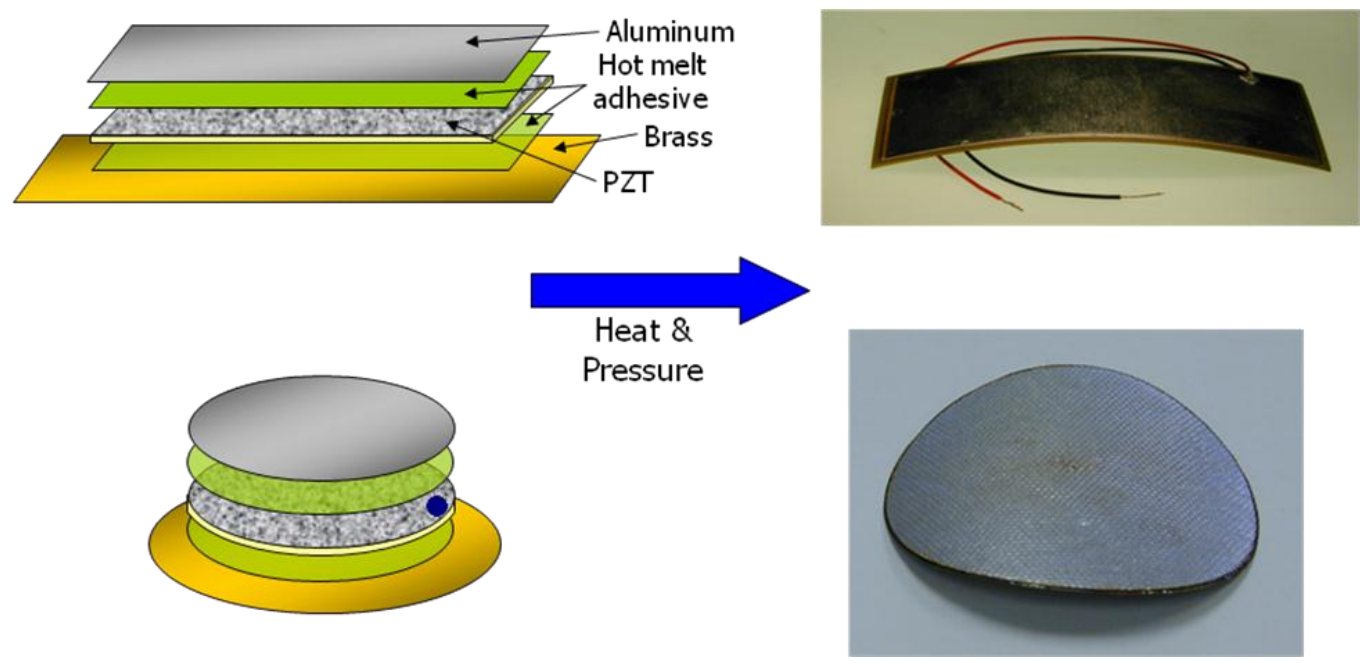

Figure 2. THUNDER Layup.

\section{MFC Actuator}

The precursor to the MFC actuator is the Active Fiber Composite (AFC) actuator developed by MIT in the mid '90s, under a DARPA funded program, and later offered for sale by Continuum Control Corp (Figure 3). 


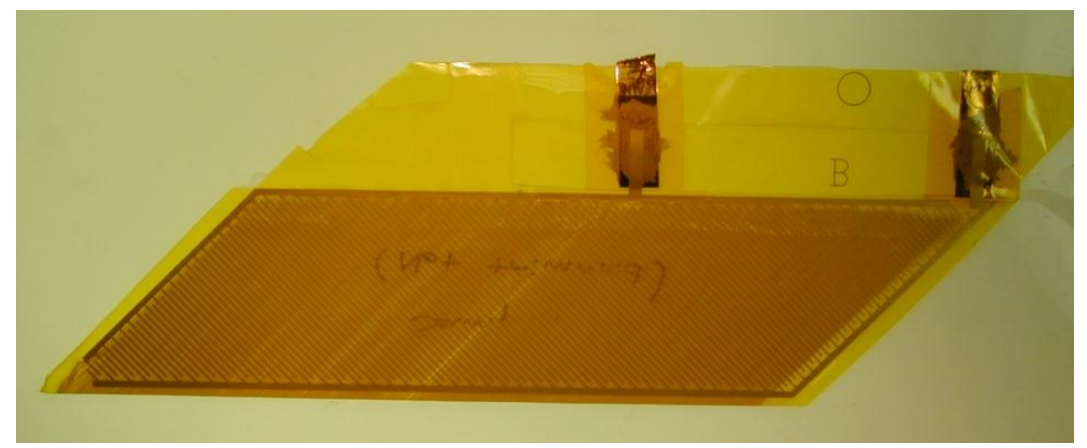

Figure 3. The Active Fiber Composite Actuator.

The Macrofiber Composite is similar in construction, but enhanced for manufacturability, quality control, and mechanical efficiency. The first difference in assembly is that the MFC starts from unelectroded piezoelectric plates mounted on a frame with releasable grip tape. These plates are placed in a wafer saw and diced to produce a layer of evenly spaced square fibers. The exposed fibers are partially bonded to the etched interdigitated copper electrodes on the Kapton ${ }^{\circledR}$ film. Next, the grip tape is peeled back, exposing the top side of the piezoelectric fibers. The top layer of patterned Kapton ${ }^{\circledR}$ film, electrode side down, is aligned over the exposed fibers producing an encapsulated assembly that is subsequently cured in a hot press (Figure 4). [16] The MFC uses conventional processed wafers that do not have an inactive surrounding oxide layer; the fibers have a rectangular cross section providing continuous surface contact with the electrodes, thereby minimizing any geometric electric field gradients. Lastly, all the materials used are available from multiple venders, preventing issues with sole source suppliers. [17]

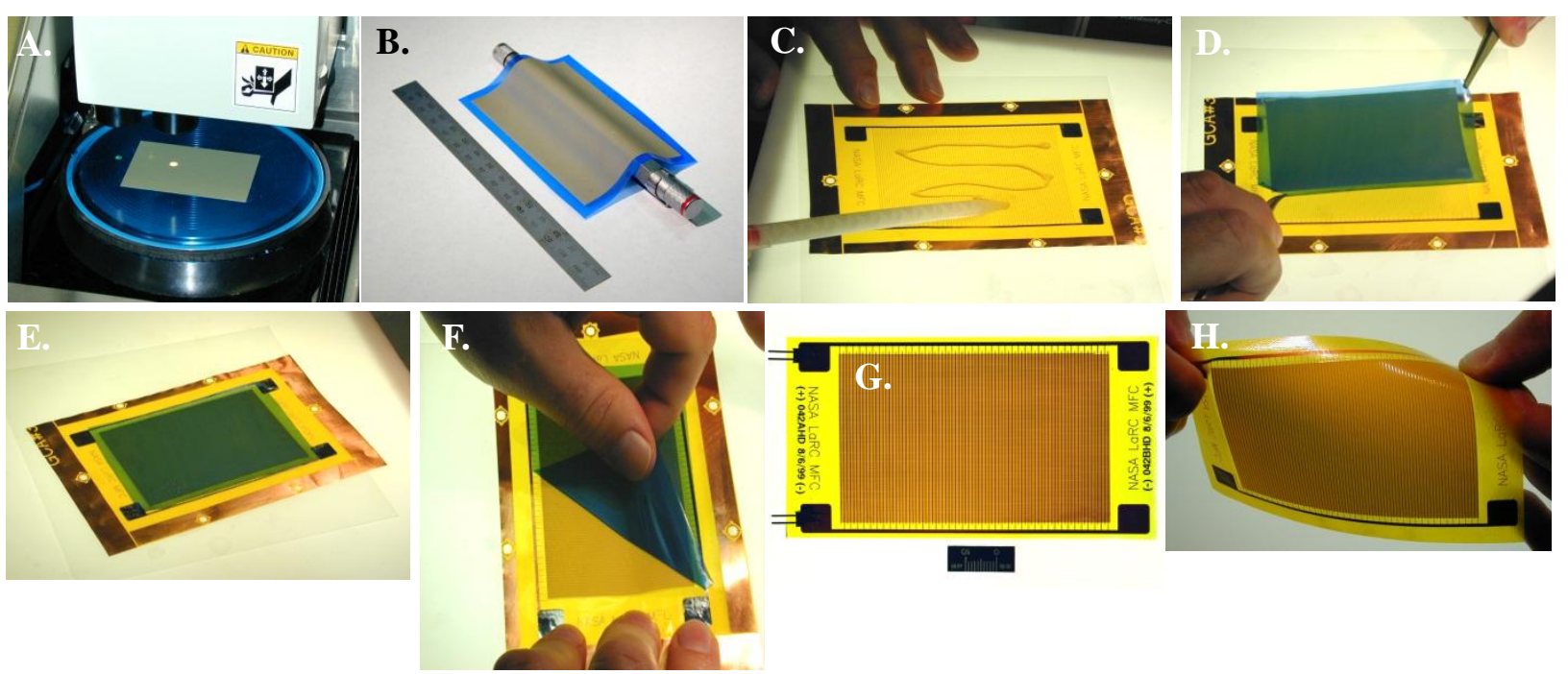

Figure 4. MFC fabrication; A. Slicing Wafer on dicing saw, B. Aligned rectangular fibers on Grip film, C. Applying adhesive to copper-etched Kapton ${ }^{\circledR}$ film, D. Placing fiber mat face down on adhesive, E. Bonded fiber-mat on etched Kapton ${ }^{\circledR}$ film, F. Peeling back Grip film, G. Finished MFC, H. Flexible MFC demonstration.

Discussion:

As a Government Laboratory pursues its various missions, technologies and products are developed. One of the roles is to make the technologies available to the private sector to create products that increase our standard of living and benefit our economy through trade. [18] The Technical Readiness 
Level (TRL) is a qualitative measure used to assess the risk of a particular technology based on technical progress. The higher the TRL, the less risky, the lower the TRL, the larger the application space is for a technology. These TRLs are redefined depending on the technology area and the technology sector. $[19,20]$ During the maturation of a technology into a product, there is some overlap in the TRLs, and a general "rule of thumb" is that the cost doubles for each TRL number advancement. The higher the TRL of a given technology, the less risky the initial investment is towards making a product. In order for the technologies to be considered for additional funding, a certain TRL should be reached during their development. At NASA, the three technologies, LaRC-SI, THUNDER and the MFC, were developed to demonstrate the potential to provide products that would enable particular missions. However, the actual process of inventing through licensing is not a straight-forward operation as there are several important obstacles related to risk, cost and ideology that have to be overcome.

LaRC-SI was originally developed under NASA's HSR program which focused on developing a Mach 2+, 300+ seat High Speed Civil Transport (HSCT) with a gross takeoff weight of $~ 750,000 \mathrm{lbs}$ having a non-stop range from Los Angeles to Tokyo ( 5000 nautical miles). [21] NASA screened several dozen combinations of polymer systems from commercial monomers (base feedstock chemicals) and developed several polyimide resins that were more successful for meeting the advanced composite property requirements for the High Speed Civil Transport. [22] Although LaRC-SI had similar outstanding physical characteristics, as would be expected from this class of melt-processable aromatic polyimides, what set LaRC-SI apart were the unexpected attributes that were not predicted from known structure-property relationships. It was felt that these unique properties could be taken advantage of; its behavior during resin synthesis, its broad melt processing characteristics, and its ability for being used for a wide range of applications. The promotion of this new material involved performing the requisite lab work and standardized testing, developing the intellectual property and getting the funding to support the research during the time that the production of the base chemicals were being moved out of the US. As a coincidence, other companies were developing IP along similar lines of research. This meant leaving a well-funded highly visible national program and seeking other technology areas that would be supported by other NASA missions during the time when other institutions were pursuing closely related technologies.

The first hurdle was in securing the supply of raw materials that effected many high performance resin systems including LaRC-SI. The production of the base monomers to make LaRC-SI were becoming unavailable in the US, this is a constant problem for Federal labs as they are prohibited from direct purchases from foreign entities. If the volumes of material are not of sufficient quantity, the foreign producers of these materials have little incentive to locate a distributor in the US, and might place strict controls on their pricing and availability. Faced with this supply problem during the HSR program, NASA's Small Business Innovative Research (SBIR) program was used to incentivize the small business community to synthesize and become a commercial source for these chemicals within the US, then demonstrate the capability to use these materials to produce the resin systems needed to support the HSR program. The monetary incentive for the small business was: 1) to have the SBIR program help fund the commercial development of these chemicals and resins; 2) the initial customer for these resins, during their evaluation, would be the HSR program; and 3) the company would have a major supply contract if the Original Equipment Manufacturer (OEM) selected the composites, based on these resins, to build the HSCT. The business motive was that these chemicals and NASA resins would be available in the US, and had the potential to be used for other products beyond advanced structural composites.

Although LaRC-SI was now commercial product, minimal sales were taking place because there were no applications requiring its use. In order to find or create a market for this polymer, four approaches were used: 1) the distribution of technical literature (Journal articles, Patents, Presentations); 2) the cooperation of the technical staff to make themselves available to interested parties through "general interest" magazine articles, trade show appearances and reimbursable work; 3) an external source for purchasing LaRC-SI, and 4) demonstration hardware created with LaRC-SI. Initially, most of this type of work did not pay off. When one of first two approaches was initiated with a potential 
customer, the standard result was that no follow-on correspondence took place. However, that did not mean nothing was happening, LaRC-SI was being sold, in small quantities. The demonstration hardware was done as part of the SBIR program, where the small business was required to deliver samples of LaRC-SI resin, molding powder, and mechanical parts (gears, rings, plaques, etc). The resin and the molding powder were used for thermal and mechanical evaluation. A traveling display was created from some of these test articles, the mechanical parts, and one page glossy handout specification sheets. This helped our traveling in-house and contractor marketing staff when discussing LaRC-SI and the potential applications with external customers.
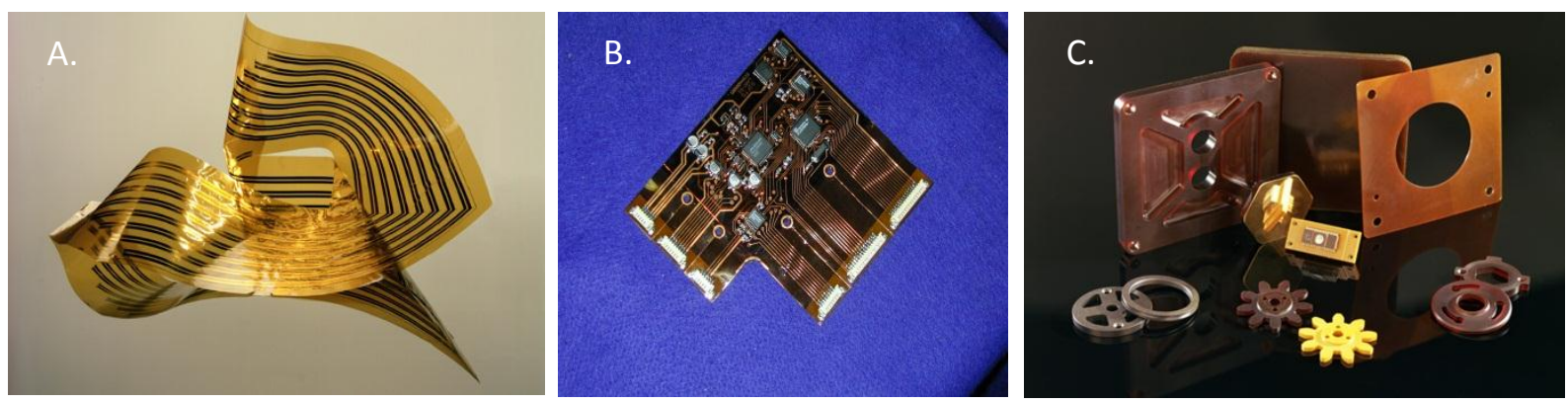

Figure 5. A. >0.5 mil Flex cable (NASA), B. Flexible high-speed multilayer adhesiveless A-D converter circuit (NASA), C. Mechanical parts (Imitec Inc.).

There was enough interested from these interactions that NASA and several companies entered into cooperative agreements to test the product for their internal applications. The majority of these applications were not realized because many of the companies did not have the requisite equipment, they were doing fine with their existing products, or their market was too price sensitive to make the investment in a better but more costly technology. NASA's only enduring capital were the patents offering protection, the technical literature that could be sent to interested parties for review, the ability to buy LaRC-SI from an industrial source, and a 1995 R\&D 100 Award. What LaRC-SI needed to sustain it was a killer app, a technology that has a recognized application that used LaRC-SI, but in a different market sector. When the THUNDER actuator was developed, it was developed using LaRC-SI material and thus, became the killer app, as its market applications were completely different than LaRC-SI. [24]

The THUNDER prototypes were initially developed as unfunded "bootlegged" effort. The inspiration for the THUNDER actuator came from a pre-stressed unimorph concept, called RAINBOW (Reduced And InterNally Biased Oxide Wafer), developed at Clemson University by Dr. Gene Haertling, and later licensed and offered for sale by Aura Ceramics (Figure 6). [24]

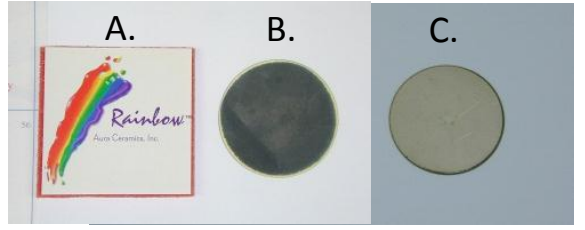

Figure 6. RAINBOW PZT Actuator (Aura Ceramics): A. Box, B. Bottom View, C. Top View.

The similarity between the RAINBOW and THUNDER actuators is that they use the CTE differential of their constituent materials to create an internal pre-stress that amplifies their displacement. The difference is in how they achieve this pre-stress through processing. The RAINBOW obtains its curvature by chemically reducing some of the lead oxide, in the PZT ceramic, on the underside of the wafer through a reactive thermal process that produces a chemically different material. Upon cooling, the differential material gradient evenly strains the wafer forming a curved actuator. Thus, the RAINBOW uses chemical reduction to develop its pre-stress, the THUNDER actuator obtains its pre-stress through thermally 
developed mechanical shear strain. The following diagram (Figure 5) outlines the differences in their processing.

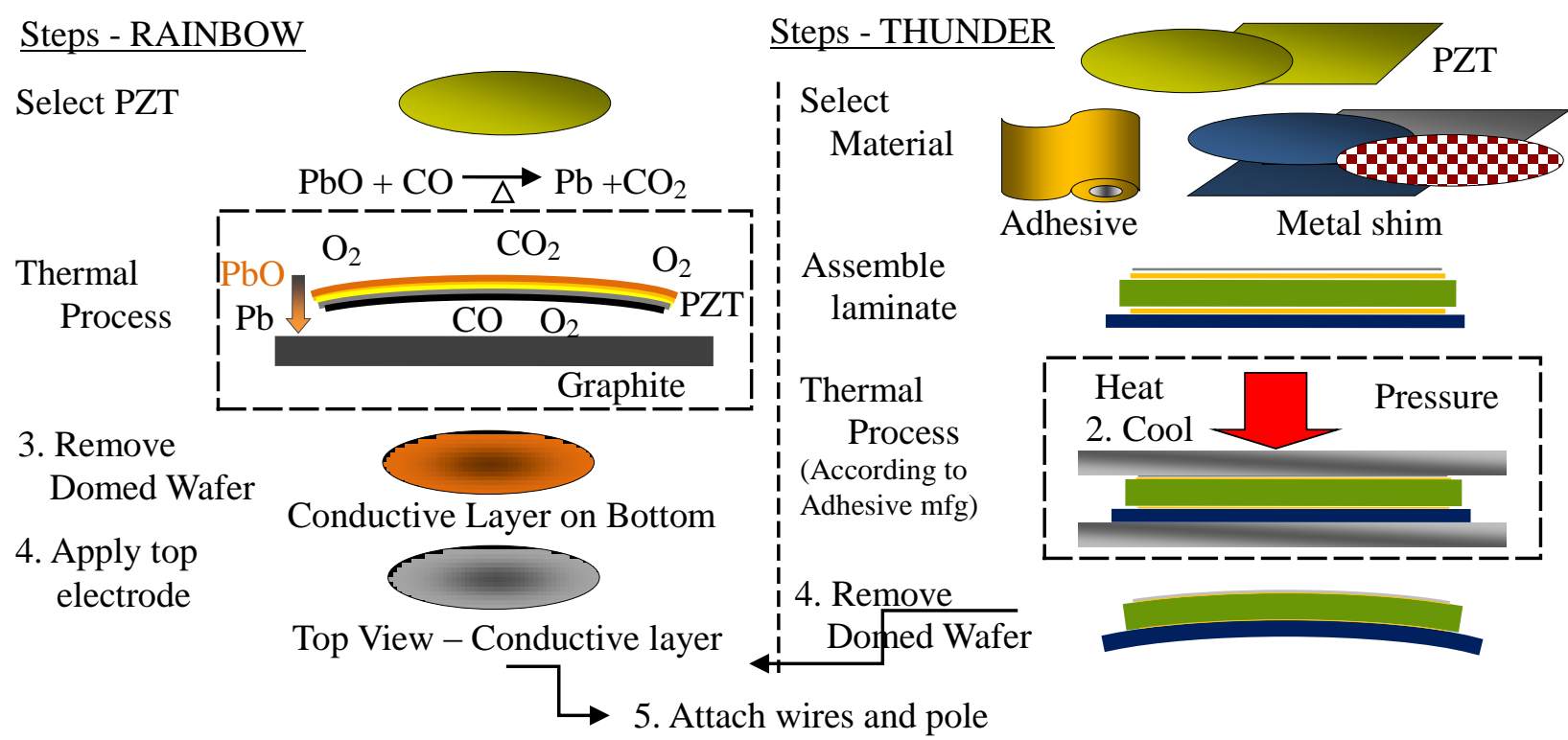

Figure 5. Comparison of the RAINBOW and THUNDER processing methodologies.

As shown in Figure 5, there are several advantages to the THUNDER wafer, the selection of materials makes the wafer highly configurable, the pre-stress layer can also serve as a mounting frame, and the process is repeatable. Furthermore, the assemblage adds to the robustness of the device as the electroactive ceramic is protected by tougher materials, and electrical lead attachment offers the choice of soldering or flat wire leads placed in-situ during fabrication. Although the function of the adhesive plays a critical role, there are a variety of hot melt adhesives that could be used. However, for the introduction of a new device with test data and application demonstrations, LaRC-SI was selected as the hot-melt adhesive. This reasoning behind this was to help promote the sales of LaRC-SI and if external customers wanted this actuator for their own products, they would initially focus on using LaRC-SI to make these actuators for performance consistency. Further development of the THUNDER actuator was funded by the New Millennium Satellite program. NASA's application was to develop a lightweight solid-state motor drive unit for an in-space interferometer. THUNDER was awarded a 1996 R\&D 100. After this actuator was licensed, sales of THUNDER began as external R\&D programs and product development took place. Unfortunately, the THUNDER actuator uses only a small amount of LaRC-SI film, and the majority of the initial sales of the THUNDER wafer were for research-type activities for technology demonstrations. Some examples of the prototypes for applications are shown in Figure 6. [25-27]
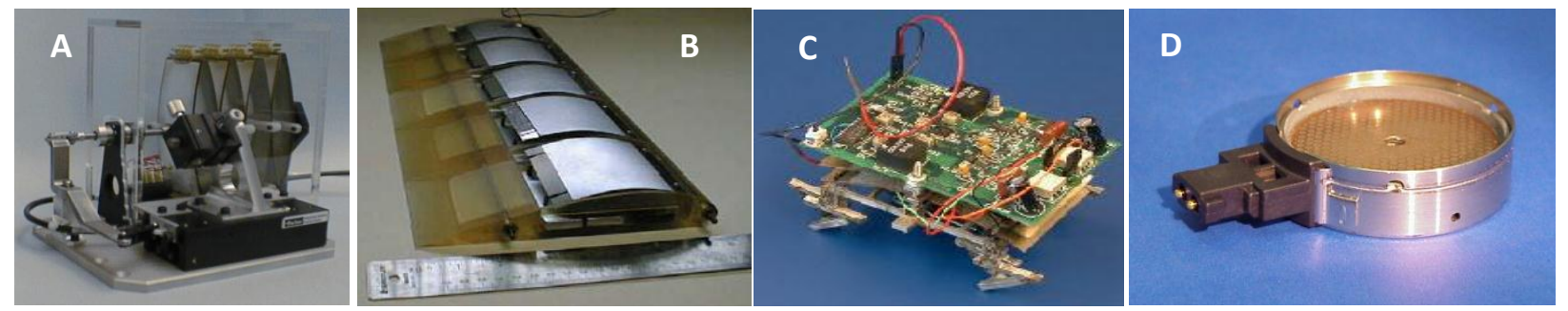

Figure 6. A THUNDER Piston-Motor (NASA), B. Dynamic Airfoil (NASA), C. Robot crawler (DARPA), D. Diesel Valve Injector (Caterpillar). 
The most important aspect of the THUNDER wafer, as compared to the RAINBOW actuator, was that the manufacturing process produces actuators with less variance and more predictable performance than the RAINBOW process. These actuators are easier to implement as components, more physically robust, and since any material component can be readily changed without affecting the process, the THUNDER actuators can be readily customized as per application. Hence, the applications where this actuator could compete were systems that required a low profile or flat transducer.

Similar to the THUNDER actuator, MFC was a manufacturing improvement based on a previous concept, the AFC. The developments of both were sponsored by US Government programs, the MFC being initially sponsored by the Army's Active Twist Rotor program, with additional funding from NASA Langley's Morphing program. Originally, these actuators were developed to be embedded along part of the length of the composite blades of a helicopter's main rotor. The idea was to be able to actively pitch the blades, during rotation, thereby replacing the complex mechanical swash plate and control tubes that currently perform this function. Since these devices are piezoelectric, response time is well within their bandwidth. This type of electromechanical control system is much lighter and should require less maintenance and machinery than the current servo-mechanical actuator. Unfortunately, the process used to make the AFC actuators resulted in a wide variance in properties. This rendered them unreliable for system implementation and therefore, undeliverable within the time constrain required. The focus of the MFC process was using all COTS materials, eliminating sole source bottlenecks, and common industrial processes that allowed for ready out-sourcing of the various production steps, as required. Faced with the possibility of canceling this program, the MFC process was designed and several prototypes were made and tested. This resulted in the 2000 R\&D 100 Editor's Choice Award. The targeted use of these types of actuators was for structural control of surfaces, where adjustable low strain-high force was needed in a flexible two-dimensional format. Again, once a licensee was found, the sales of this system were slow as this was a device looking for a product. By this time, the Active Twist Rotor Program had switched internal departments and was not a major focus of NASA's rotorcraft research. Thus, the MFC became another product looking for an application, generating sporadic sales, some of these prototypes are shown in Figure 7. [28]
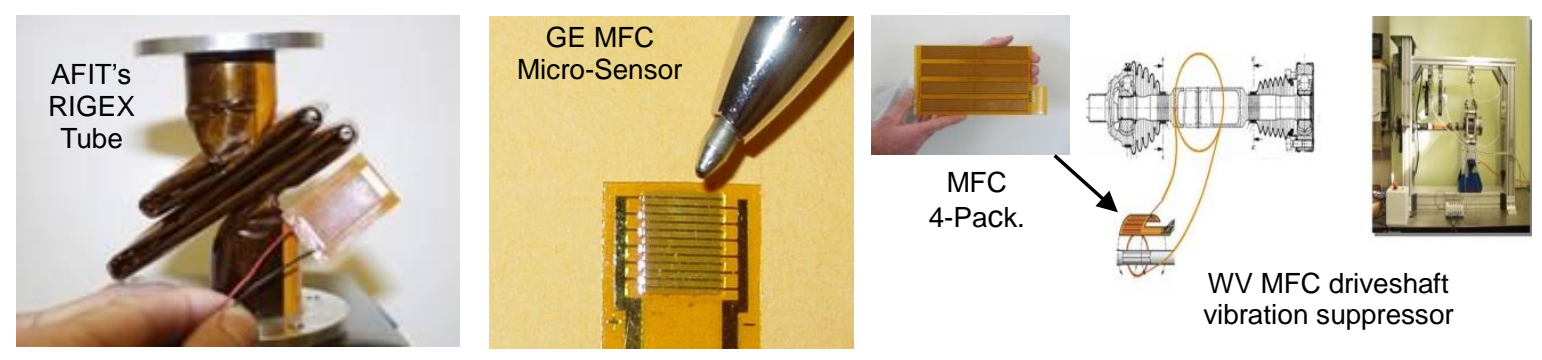

Figure 7. Examples of MFC prototype hardware, made by Smart Material Corp., and tested by external customers.

It has been over a decade for LaRC-SI, THUNDER and the MFC, so what has transpired, and what has been learned. LaRC-SI is now used as a wire coating for medical devices. [29] The THUNDER Actuator is used as a transducer in a self-powered switch [30] and the MFC is used as a force sensor control in the SWAC line of robotic welding heads, and may be on its way to become part of an active deicing system. [28,31] These are the areas that these technologies were not envisioned when they were commercialized. 

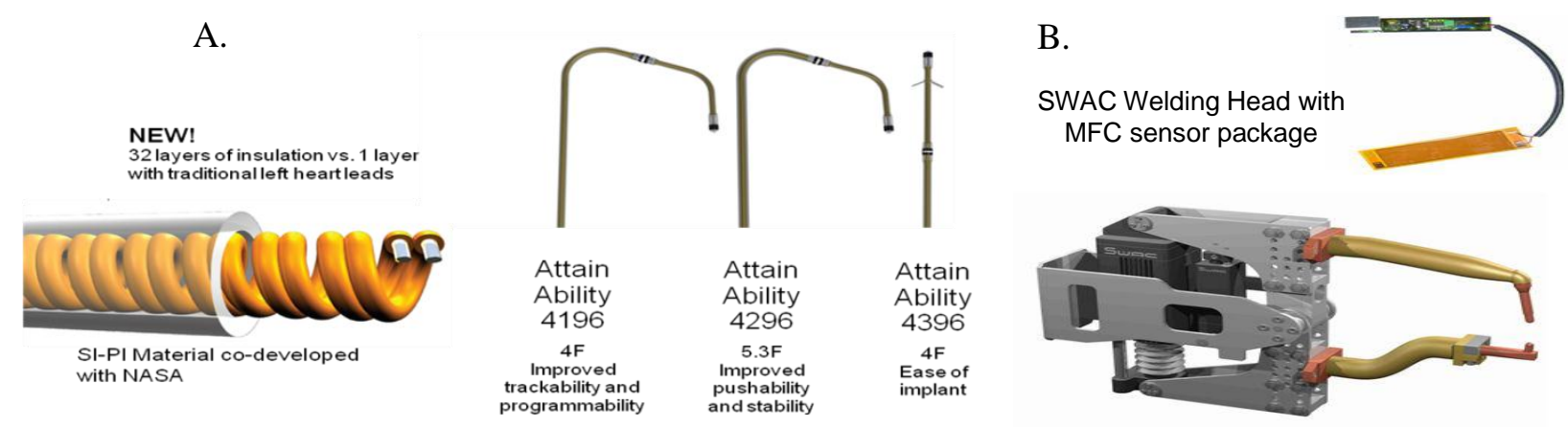

Figure 8. Examples of Products using NASA developed technology; A. Medtronic Corp. Attain Ability ${ }^{\circledR}$ Family (LaRC-SI), B. SWAC Welding head sensor (MFC).

There are several lessons learned from the process of going from the lab to the marketplace. The first lesson is appoint a person, within the technical group, who will serve as the external interface for that group to keep external communication with the business and marketing team streamlined. The second lesson is to select a non-technical different person to serve as the interface for the business, marketing and legal team. These two group leaders work with each other to pass along and retrieve information so that the members of their respective groups can remain focused on their tasks. This is important as these group leaders streamline communications, eliminate distractions, and establish trust with their respective groups and external customers. The third lesson is to secure enough resources to create the assets needed to sustain the technology between funding cycles, or to make preparations before the initial funding runs out. The only thing most inventors should do during this time, other than IP, is,

- generate data and be ready to publish technical papers,

- present at conferences where a target audience is,

- make prototype hardware and samples with a one-page data/description sheet and,

- enter an invention competition.

The purpose here is low cost marketing. Conferences reach a target audience at a common location. Technical papers provide reviewed written data that is accessible, and can be examined at any time convenient to a potential customer. This helps support justification for additional funding through proposals and grants. Should the technology win an award, the trade magazines, that reach thousands of people, will feature it at no cost. If the team does not have to pay for IP (patents) then the IP must come before any publications or public display. If IP is a monetary issue, then the determination to protect the invention is; will the costs be recovered? A patent does not mean that an invention can be sold. If the invention relies on other patented technology, the sale of that invention without agreements from other patent holders constitutes infringement. Secondly, if the invention is difficult to reverse engineer, a better choice would be keeping the production methods or process a trade secret. Therefore, in addition for paying for a patent(s) or not, a market clearance search should be considered. The next step is to seek a licensee, start a company or, switch careers and work for the company that licensed the technology. The questions are,

- Are all the steps, from supply chain and material costs to a proven method of manufacturing consistency accounted for?

- Is there a market, what is the current competition, and why would a customer switch?

- What are the current related technical assets and what are their costs and value?

- What are the future career risks and how are they mitigated?

- Is the "hype" real?

These are all economic questions; how long until profit is realized. When seeking a licensee, there must be an internal champion of the technology at the licensing entity, otherwise, there is a very good chance 
the technology will not go anywhere. It may take a while before a licensee is found, so any technical assets, like papers, additional data and samples, allow a continuous low cost presence in the marketplace. Furthermore, having a supply chain and a pathway for manufacturing scale-up reduces the risk of producing the technology. This is attractive because the licensee can spend their time making the article, rather than trying to figure out how to cost effectively make the article. Displacing a known technology or product is a long and difficult process, this is especially true if there are no customers with an application. Therefore, it is important to understand the marketplace (application, cost) and the current competition (existing infrastructure, perception of flaws versus reliability). Many initial start-up companies are typically under-capitalized or highly leveraged. This means that they either don't have the money to implement production, or they may have unreasonable time-constraints as they have to make money quickly. Companies that already have related commercial products have cash flow. These companies have the ability to spend time learning a new product, adjusting processes, and may have ready customers. Lastly, is the licensee intent on producing the technology or putting it on the shelf? Does the technology interfere with another product they have, or they just want to keep their competition from releasing it? Could the inventor-team live with, or should they guard against that possibility? A 5-10 year plan, depending on the technology, for going from a laboratory technology to a product application is detailed in Table 2, below.

Table 2. Example of a Stepwise Process for Technology and Product Maturation.

\begin{tabular}{|c|l|}
\hline Step & \multicolumn{1}{|c|}{ Process } \\
\hline 1 & Demonstrate Lab scale repeatability with well written tested procedures, signed lab notebooks. \\
\hline 2 & Run initial tests (ASTM, MIL, etc). \\
\hline 3 & Demonstrate base products (make something with the technology). \\
\hline 4 & Strategize workflow, IP implementation; organize test data into pending publications. \\
\hline 5 & Apply for IP, Trademark, generate internal supply chain documentation, and publish papers. \\
\hline 6 & Attend Technical conferences with technology data and potential applications. \\
\hline 7 & Locate and contract vender or toll manufacturer (see Step 1). Public availability is key! \\
\hline 8 & Apply for funding for application development using the vender made technology. \\
\hline 9 & Locate a licensee (could be the vender). The R\&D lab work is essentially complete. \\
\hline 10 & Perform (ASTM, MIL etc.) tests based on licensee's supplied product, if needed. \\
\hline 11 & Strategize and create marketing campaign. \\
\hline 12 & Make "Show and Tell” hardware, handouts, etc. \\
\hline 13 & Attend technical trade show exhibition areas with vendor product data and demo. hardware \\
\hline 14 & Start on version 2.0. \\
\hline
\end{tabular}

Conclusions:

The three technologies, LaRC-SI, THUNDER, and MFC, started at different development phases; LaRC-SI was created from feedstock chemicals, the THUNDER actuator used some COTS technology, and the MFC used all COTS materials. The approach to marketing these technologies was very similar, and the process for getting vendors to offer each of the technologies to the public was realized. For these technologies, there was no apparent time correlation relating the initial technical starting point, the technology offered for sale to the public, and the introduction of the first sustainable marketplace product. This would indicate that the risks of implementing these technologies, by the licensee, were all at the nearly the same TRL.

When licensing technology, the major question a potential licensee has is "how and when will profit be realized?" From a licensor standpoint, this question is difficult to answer. Therefore, there are several things that must be done to help approximate a timeline. The technical risk of manufacturing must be reduced to near practice, reliable statistical data needs to be available, selection of the best route 
to protect the technology must be undertaken, and a plan needs to be in place to advance a promising technology. Preparation, timing, and TRL are critical. Lastly, many technologies and their associated products may take 5 to $10+$ years from first reduction to practice. Thus, it is important to get a technology into the public sector as soon as possible, so each customer's internal champion(s) can develop products. Lastly, a balance of persistence, technical objectiveness and market knowledge are required to know when to keep going or move on to the next endeavor.

\section{References:}

1. "Polyimides, Fundamentals and Applications", ed. by Malay K. Ghose and K. L. Mittal, published by Marcel Dekker Inc., New York, NY, 1996.

2. Robert G. Bryant, "Polyimides", Encyclopedia of Polymer Science and Technology. ed. Hermann Mark, Published by. John Wiley \& Sons, New York, NY, 7, 529, (2003).

3. R. G. Bryant, "LaRC"TM_SI: A Soluble Aromatic Polyimide”, $\underline{\text { High Performance Polymers, }}$ 8(4), 607, (1996).

4. R. G. Bryant, “Tough, Soluble, Aromatic Thermoplastic Copolyimides”, US Patent 6,048,959 (2000).

5. R. G. Bryant, “Tough, Soluble, Aromatic Thermoplastic Copolyimides”, US Patent 5,741,883 (1998).

6. R. G. Bryant, "Process for Preparing a Tough, Soluble, Aromatic, Thermoplastic Copolyimide", US Patent 5,639,850 (1997).

7. http://www.morganelectroceramics.com/resources/

8. R. F. Hellbaum, R. G. Bryant, R. L. Fox et al., "Thin Layer Composite Unimorph Ferroelectric Driver and Sensor", US Patent 5,632,841 (1997).

9. Alan R.D. Curtis, "A Model of the THUNDER Actuator”, BBN Tech. Memo. No. 1190, December 31, 1997, NASA Contract NAS 120101, Task Assignment No. 17.

10. K. M. Mossi, G. V. Selby and R. G. Bryant, Thin-Layer Composite Unimorph Ferroelectric Driver and Sensor Properties, Materials Letters, 35(1), 39, (1998).

11. Barmac K. Taleghani, Joel F. Campbell, "Non-Linear Finite Element Modeling of THUNDER Piezoelectric Actuators", NASA/TM-1999-209322 / ARL-TR-1977, May 1999.

12. Robert Wieman, Ralph C. Smith, Tyson Kackley, Zoubeida Ounaies, Jeff Bernd, "Displacement Models for THUNDER Actuators having General Loads and Boundary Conditions", NASA/CR2001-211061 / ICASE Report No. 2001-25, September 2001.

13. Mossi, K., Bryant, R., and Mane, P. "Piezoelectric composites as bender actuators.", Integrated Ferroelectrics, 71, 221-232. (2005).

14. Bryant, R. G., Mossi, K. M., Robbins, J. A., and Bathel, B. F. "The correlation of electrical properties of prestressed unimorphs as a function of mechanical strain and displacement." Integrated Ferroelectrics, 71, 267-287, (2005). 
15. Mossi, K., Mouhli, M., Mane, P., Smith, B., and Bryant, R. "Shape modeling and validation of stressed biased piezoelectric actuators," Smart Materials and Structures , 15, 1785-1793, (2006).

16. James W. High and W. Keats Wilkie, "Method of Fabricating NASA-Standard Macro-Fiber Composite Piezoelectric Actuators", NASA/TM-2003-2 12427 / ARL-TR-2833, June (2003).

17. W. K. Wilkie, R. G. Bryant, J. W. High, R. L. Fox, R. F. Hellbaum, A. Jalink, Jr., B. D. Little, P. H. Mirick, "Low-Cost Piezoceramic Actuator for Structural Control Applications", Proceedings of the SPIE - Smart Structures and Materials: Industrial and Commercial Appl. of Smart Structures Tech., 3991, 323, (2000).

18. Stevenson-Wydler Technology Innovation Act of 1980, Pub. L. No. 96-480, as amended, 15 U.S.C. § 3701 et seq.

19. http://en.wikipedia.org/wiki/Technology_readiness_level

20. John C. Mankins, “Technology Readiness Levels, A White Paper”, Advanced Concepts Office, Office of Space Access and Technology NASA, April 6, 1995: http://www.hq.nasa.gov/office/codeq/trl/trl.pdf

21. D. R. Tenney, J. G. Davis, Jr., N. J. Johnston, R. B. Pipes and J. F. Mcguire, "Structural Framework for Flight: NASA's role in the Development of Advanced Composites for Aircraft and Space Structures", NASA/CR-2011-217076, May 2011, Chapter 6.

22. Ibid., Chapter 11.

23. Ben Bruneau, "Featured Invention: Langley Soluble Imide", NASA ASK Magazine, 33-34, Summer (2006).

24. G. H Haertling, "Rainbow Ceramics - A New Type of Ultra-High Displacement Actuator," Am. Ceram. Soc. Bull., 73, 93 (1994).

25. R. G. Bryant, S. A. Evans, E. R. Long Jr., and R. L. Fox, "Thermal and Mechanical Characterization of NASA High Displacement Actuators For Satellite Instrumentation", Proceedings of the SPIE - Smart Structures and Materials: Industrial and Commercial Appl. of Smart Structures Tech., 3991, 195, (2000).

26. Jennifer L. Pinkerton and Robert W. Moses, "A Feasibility Study To Control Airfoil Shape Using THUNDER”, NASA TM 4767, November 1997.

27. Glenn Waterfield, "High Performance Pre-stressed Piezoelectric Bender Actuator for Digital Valves", Ceramic Transactions, 150, 424-440, (2004).

28. http://www.smart-material.com/MFC-product-main.html

29. http://www.nasa.gov/topics/nasalife/features/larc-si.html

30. http://www.lightningswitch.com/

31. http://www.swac.de/ 